\title{
(Re)making data markets: an exploration of the regulatory challenges
}

\author{
Linnet Taylor (TILT, Tilburg University, NL) \\ Hellen Mukiri-Smith (TILT, Tilburg University, NL) \\ Tjaša Petročnik (TILT, Tilburg University, NL) \\ Laura Savolainen (Centre for Consumer Society Research, University of Helsinki, Finland) \\ Aaron Martin (TILT, Tilburg University, NL)
}

\begin{abstract}
Regulating the data market is shaping up to be one of the major challenges of the twenty-first century. In order to think about regulating this market, however, we first need to make its dimensions and dynamics more accessible to observation and analysis. In this paper we explore what the state of the sociological and legal research on markets can tell us about the market for data: what kind of market it is, the practices and configurations of actors that constitute it, and what kinds of data are traded there. We start from the subjective opacity of this market to researchers interested in regulation and governance, review conflicting positions on its extent, diversity and regulability, and then explore comparisons from food and medicine regulation to understand the possible normative and practical implications and aims inherent in attempting to regulate how data is shared and traded. We conclude that there is a strong argument for a normative shift in the aims of regulation with regard to the data market, away from a prioritisation of the economic value of data and toward a more nuanced approach that aims to align the uses of data with the needs and rights of the communities reflected in it.
\end{abstract}

Keywords: big data, competition, data protection, data governance, regulation, data market

\section{Why research the data market?}

In March 2019 Google's parent company, Alphabet, was fined $€ 1.49$ billion by the European Commission for stifling advertising competition. ${ }^{1} \mathrm{~A}$ few months earlier, France's data protection

\footnotetext{
${ }^{1}$ Adam Satariano, 'Google Fined \$1.7 Billion by E.U. for Unfair Advertising Rules' The New York Times (20 March 2019) <https://www.nytimes.com/2019/03/20/business/google-fine-advertising.html> accessed 9 June 2021.
} 
body, the CNIL, had fined the company $€ 50$ million for not giving its users enough information about how it uses the data it takes from them. ${ }^{2}$ And more recently in October 2020, it was revealed that companies in the UK collecting data for pubs and restaurants to help them fulfil their contact-tracing duties during the COVID-19 pandemic had been selling this data to marketers, credit companies and insurance brokers without authorisation. ${ }^{3}$ These three cases initially appear unconnected: one is about antitrust violations, the next about the GDPR and transparency in personal data use, and the third about the use of digital technology in times of crisis. What links them, however, is the data market. Our knowledge of this market is limited: its contours surface through moments of conflict such as court judgements when players are considered to have crossed a legal boundary or in media stories that report on particularly transgressive instances of data misuse. Which laws apply in the international and largely opaque space of this market, however, is not entirely clear. Commentators currently estimate its value in the trillions of dollars, ${ }^{4}$ and it is growing continually. Advertising is only one component of the larger network of data markets (which include, for example, health data, business operational data and public sector data), and little is known about the bigger picture these constitute. However, critics are arguing that not understanding data markets now has implications for national security and for the ability to carry out domestic policy, let alone for the effectiveness of privacy law and market regulation. ${ }^{5}$

We will posit in this paper that the data market is currently under-regulated, with only the highvisibility actions of a tiny number of players subject to scrutiny. Without a clearer view of how different business models interact with particular legal and commercial geographies to make up a global market, ${ }^{6}$ it is impossible to target regulation, let alone to establish meaningful scrutiny that can protect people from harm. We do not conceptualise those harms as limited to privacy, but instead as relating to the whole range of rights and entitlements people exercise through their digital selves: economic, political and social. We will argue that the component of this market visible to regulators, namely data trading by major technology firms, constitutes the tip of an iceberg and that unless we can understand the extent and nature of data trading, both public and private efforts at regulation are destined to be, at best, partial and highly limited in their effects. ${ }^{7}$ Overall, we look to make the case that global data governance is needed to complement country-level data regulation, and to explore what regulatory mechanisms and structures are required to underpin effective governance of the global data market. Despite - or perhaps due to - the opacity of the

\footnotetext{
${ }^{2}$ Google LLC v Commission Nationale de l'Informatique et des Libertés SAN-2019-001.

${ }^{3}$ Shanti Das and Shingi Mararike, 'Contact-Tracing Data Harvested from Pubs and Restaurants Being Sold On' (10 November 2020) <https://www.thetimes.co.uk/article/contact-tracing-data-harvestedfrom-pubs-and-restaurants-being-sold-on-s0d85mkrr> accessed 9 June 2021.

${ }^{4}$ Tony Rifilato, 'Ad Tech Valuations Are Sky High - But Are They Justified?' (AdExchanger, 30 April 2021) <https://www.adexchanger.com/featured-2/ad-tech-valuations-are-sky-high-but-are-theyjustified/> accessed 9 June 2021.

${ }^{5}$ Michael Kans, 'Data Brokers and National Security' (Lawfare, 29 April 2021)

<https://www.lawfareblog.com/data-brokers-and-national-security> accessed 9 June 2021.

${ }^{6}$ Julie E Cohen, 'The Biopolitical Public Domain: The Legal Construction of the Surveillance Economy' (2017) 31 Philosophy \& Technology 213.

7 This problem is further illustrated by the NHS' (the UK health provider) plan to share patient data with third parties, criticised by advocacy groups on the basis that transparency provisions only provide patients information about the intermediaries receiving the data rather than about end-users or types of use. Madhumita Murgia, 'England's NHS plans to share patient records with third parties' Financial Times (26 May 2021) < https://www.ft.com/content/9fee812f-6975-49ce-915c-aeb25d3dd748> accessed 27 May 2021.
} 
market for data, regulating it is shaping up to be one of the major challenges of the twenty-first century. This implies that its dimensions and dynamics will have to be made accessible to research if we are to understand how, or at what level, it could potentially be bounded. We can assume, however, that while we consider regulating it, it is regulating us. Markets have a mutually shaping relationship with politics and society, and the data market - in its broadest sense - is a global site of entanglements between trade and control, contoured by geographies of regulation and law. Polanyi argued that the social shaping of markets both explains and influences how we conceptualise our rights and duties toward each other. ${ }^{8}$ If this is true, then it is worth asking what a global market trading primarily in human behavioural data can tell us about the world we are building.

We do not currently have a single definition of 'the data market'. We can identify online advertising markets of the sort managed by Google and Facebook, where a data collection behemoth brokers profiles of users for firms who want to advertise to them, and rents those users' attention to the highest bidder. There are also indications that a burgeoning market is emerging around the data produced by connected objects, where behaviour and the environment are mapped, tracked and followed over time. In this market, tradeable data assets may or may not be attached to individuals: it is just as useful to be able to market to people who, for example, use an expensive electric toothbrush, have connected coffee machines which make coffee at 6am and take the metro to the city centre every day, as to individuals who identify themselves as urban professionals. There are also subtler markets circulating around and within these dominant systems. The market for mobile phone location data is a field for law enforcement, bounty hunters and bail bondsmen, ${ }^{9}$ as well as private detectives, but it also acts as a secondary market for those seeking to advertise to humans (who generate location records) rather than bots (which do not) or to 'redline' certain groups to exclude them from particular services or goods.

What is being traded in data markets? Bits of information, capital, data commodities, human labour? The nature of data as a market commodity is rather elusive and often problematic. Prainsack, for example, points to the fact that (digital) data and information rely on materiality. ${ }^{10}$ That is, they require human, natural, and artefactual tools and infrastructures to exist and be processed, yet this materiality is distributed: (digital) data is multiple and can exist and be processed in several places at the same time.

Scholars focusing on data as capital see a few huge monopolies acting as exchanges where behavioural futures derived from human raw materials can be brokered. ${ }^{11}$ In this market, those humans have little knowledge of, or ability to claim rights over, the data they produce. An alternative vision is offered by Arrieta Ibarra et al.: one of a labour market where data's value, particularly as inputs for artificial intelligence (AI) systems, depends to a great extent on human work

\footnotetext{
${ }^{8}$ Karl Polanyi, 'The Great Transformation: The Political and Economic Origins of Our Time (New York: Rinehart)'.

$9 \mathrm{~J}$ Cox, 'Hundreds of Bounty Hunters Had Access to AT\&T, T-Mobile, and Sprint Customer Location Data for Years' <https://www.vice.com/en/article/43z3dn/hundreds-bounty-hunters-att-tmobile-sprintcustomer-location-data-years> accessed 9 June 2021.

10 Barbara Prainsack, 'Logged out: Ownership, Exclusion and Public Value in the Digital Data and Information Commons' (2019) 6 Big Data \& Society 2053951719829773, 5.

${ }^{11}$ Frank Pasquale, The Black Box Society (Harvard University Press 2015); Shoshana Zuboff, The Age of Surveillance Capitalism: The Fight for a Human Future at the New Frontier of Power (First edition, PublicAffairs 2018).
} 
cleaning, tagging and labelling features that can then be translated into financial value. In this vision, data can be both capital and labour, but the value of data as traded should also be used to determine what constitutes efficient payment to data workers. ${ }^{12}$

It is helpful to think of the data market(s) through the lens of the assemblage: a collection of relationships, systems and objects that are entangled and interconnected with each other, but where we may look at the whole with the assumption that it has a meaning greater than the sum of its parts, ${ }^{13}$ its 'heterogeneous elements can hold together without actually forming a coherent whole. ${ }^{14}$ Other scholars such as Kitchin and Lauriault and Aradau and Blanke have posited the idea of the 'data assemblage' in relation to both security arrangements and smart city governance.$^{15}$ Here we build on this to conceptualise the data market as a product of the various systems - security, commercial and public - that produce and channel data for different purposes. The idea of the assemblage helps illuminate the central problem we tackle in this paper, namely understanding what 'the market' might be, given its internal diversity and multiplicity, and what this means for proposals to govern it. In particular, it helps us understand whether, if we want to conceptualise just ways of governing data on the global scale, there is value in identifying what about it can be seen as systemic, organised and inter-communicative. The assemblage perspective acknowledges both the heterogeneity of the data market and that there is something coherent about its effects that makes it worth studying as a source of systemic social change. Unlike Zuboff, who sees the way data is exploited and produces value as a result of unregulated capitalism, we interrogate the data market as something that is both purposefully created from, and generative of, a particular kind of capitalism. We posit that the global data market can be seen as an assemblage of interacting legal and market systems, whose entanglement creates a legally opaque space in which datasets can be deconstructed, reconstructed and circulated as either capital or commodity. The end product of this market assemblage, we argue, is actionable data with the potential to affect the social world.

For a decade or more, industry actors have described the data market as trading in personal data, with targeted advertising the actionable result. ${ }^{16}$ Data's tradeability as an asset, however, does not necessarily depend on its connection to individual identities. Profiles may point directly at individuals, or may be valuable because they allow models to be targeted at types, rather than tokens of individual identity. ${ }^{17}$ This type of 'non-distributive' profile makes it possible to segment on

12 Imanol Arrieta-Ibarra and others, 'Should We Treat Data as Labor? Moving beyond" Free"', aea Papers and Proceedings (2018).

${ }^{13}$ Gilles Deleuze and D Guattari, A Thousand Plateaus: Capitalism and Schizophrenia (University of Minnesota Press 1987).

14 John Allen, 'Powerful Assemblages?: Powerful Assemblages?' (2011) 43 Area 154.

${ }^{15}$ Rob Kitchin and Tracey Lauriault, 'Towards Critical Data Studies: Charting and Unpacking Data Assemblages and Their Work'; Claudia Aradau and Tobias Blanke, 'The (Big) Data-Security Assemblage: Knowledge and Critique' (2015) 2 Big Data \& Society 2053951715609066.

${ }^{16}$ Personal Data Ecosystem Consortium, <http://pde.cc/>. Consortium members in 2012: Allfiled, bitWorld, Cloudstore Technologies, Consumer Marketing Rights, COMRADITY, Lifedash, Metaconnectors, PIB-d Ltd, Planetwork, Privowny, Tangled, Virtrue; in 2011: Azigo, Buyosphere, Connect.me, archify, Gluu, Kynetx, Mydex, MyINFOSAFE, Peercraft, Personal InfoCloud, Personal, Privo, Project Danube, Qiy, Reputation.com, Singly, Synergetics, SwitchBook, The Customer's Voice. PDEC, 'Personal Data Ecosystem Consortium' (2011).<https://pde.cc/> accessed 8 June 2021. World Economic Forum, Personal Data: The Emergence of a New Asset Class (2011). New York, WEF.

17 Luciano Floridi, 'Open Data, Data Protection, and Group Privacy' (2014) 27 Philosophy \& Technology 1. 
a probabilistic basis, targeting those likely to have the attributes of interest (i.e. those correlated with a willingness to buy a particular product at a particular price). Such trading in profiles could be described as a market in data derivatives, where models, hypotheses and combinations of inputs are traded rather than signals from individuals. This has implications for the central role currently posited for data protection regulation in relation to international data markets: if what is traded is not personal data but data derivatives such as profiles and insights which may not relate to individuals directly, yet which have the kind of effects privacy rights and data protection are designed to prevent, then data protection cannot be expected to do the job of market regulation on its own.

Where are these assets being traded? All markets have a geography. The data market is both demonstrably global and based on material infrastructures such as server farms, fibre optic cables and the entire apparatus of mobile networks - an infrastructure that is thicker in some places than in others and which may provide a way to look at how the market operates, ${ }^{18}$ but as yet these regional contours have been inferred by research on the data being traded, rather than comprehensively mapped. Upturn's 2017 report demonstrated that it was possible to research markets rather than practices, ${ }^{19}$ and interdisciplinary scholarship in computer science and law is starting to offer clues on how to do so. ${ }^{20}$ Yet research that addresses how the market(s) for data may be influenced by regional or country characteristics is still sparse. Research on Europe by Helles et al. shows that the market for cookie data is geographically uneven, with different practices and players emerging in relation to particular linguistic or cultural groups rather than by country or region. ${ }^{21}$

These questions add up to a rationale for mapping, analysing and thus conceptualising the data market. Unless we know more about its scope, dynamics and criteria for assigning value to data, and unless we can find ways to identify how these are similar or different across regions, we cannot predict how the trade in data will affect our societies and our economies and, in turn, posit how to control negative effects of trade in data. It is hard to imagine, for example, a world where stock markets exist but we do not know how they are affecting our economies or our currencies, or how they shape incentives for powerful corporations. Yet this is the situation in which we find ourselves with regard to the data market. If we wish to engage in planning and design, either economic or social, in relation to our rapidly digitising world, if we wish to regulate corporate behaviour or promote human rights, then we need to know something about the target of interest. This paper aims to set the parameters and an agenda for analysing the data market, and to scope the benefits of doing so on the global - rather than the local - level.

To do so, we will begin by offering a theoretical framing of the market, in order to determine which features of the ideal type the data market shares. We will outline the state of the art in research on the data market: what is known, what is unknown, and how this fits (or does not) with theories on

${ }^{18}$ Craig M Dalton, Linnet Taylor and Jim Thatcher (alphabetical), 'Critical Data Studies: A Dialog on Data and Space' (2016) 3 Big Data \& Society 205395171664834.

${ }^{19}$ A Rieke and others, 'Data Brokers in an Open Society' (Open Society Foundation 2016) $<$ https://dare.uva.nl/search?identifier=073577f4-daa0-4bb8-9e9c-7bf8cc7228fd > accessed 9 June 2021.

${ }^{20}$ Reuben Binns and others, 'Third Party Tracking in the Mobile Ecosystem', Proceedings of the 10th ACM Conference on Web Science (2018).

${ }^{21}$ Rasmus Helles, Stine Lomborg and Signe Sophus Lai, 'Infrastructures of Tracking: Mapping the Ecology of Third-Party Services across Top Sites in the EU' (2020) 22 New Media \& Society 1957. 
markets, looking in particular at the phenomenon of 'dark pools', or highly localised trading hubs formed to facilitate block trading and which are opaque to regulators. Moving to the question of how the data market could, or should, be governed, and by whom, we will then explore regulatory models from other sectors that offer new ways of thinking about regulating this kind of market.

We do so using insights from the critical data studies and data justice literature, ${ }^{22}$ which posit that data should be regulated not for its economic effects but for its effects on human wellbeing and dignity. As Floridi argues, "my" in "my data" is not the same "my" as in "my car", it is the same "my" as in "my hand", because personal information plays a constitutive role of who I am and can become. ${ }^{23}$ In line with this human-focused body of research on data, we purposely select cases for comparison - namely international markets for food and medicine - which at first sight are not usual comparators for the data market. We do so to highlight that the regulation of data is mainly approached as one of minimising obstacles to its free flow internationally, and of maximising the financial value that can be extracted from it. ${ }^{24}$ Over the last decade has involved normalising the assumption that data, like money, is a commodity which in order to deliver its value must be separated entirely from the people involved in generating and using it. This makes the regulation of financial markets the most intuitive heuristic for innovation in data regulation. ${ }^{25}$ We agree with Aaronson that 'data is different', but take this insight further to argue that, when thinking about regulating the market for it, we should use comparators that both highlight its local human effects and start from the assumption that the link between data and human wellbeing cannot be invisibilised when considering regulatory approaches.

\section{What is a (data) market? An overview of the state of knowledge}

In this section, we explore work by classic economic thinkers and contemporary social theorists on what has been said about markets in general, in order to help make sense of data markets and their political economy. If we are to understand the regulatory landscape, it is important to be able to evaluate the arguments that market actors themselves present for the public. For example, it is not uncommon to hear that regulation is an artificial intervention in the 'naturally' unfolding dynamism

\footnotetext{
22 Linnet Taylor, 'The Ethics of Big Data as a Public Good: Which Public? Whose Good?' (2016) 374 Philosophical Transactions of the Royal Society A: Mathematical, Physical and Engineering Sciences 20160126; Richard Heeks and Satyarupa Shekhar, 'An Applied Data Justice Framework: Analysing Datafication and Marginalised Communities in Cities of the Global South' 27; Os Keyes, Jevan Hutson and Meredith Durbin, 'A Mulching Proposal: Analysing and Improving an Algorithmic System for Turning the Elderly into High-Nutrient Slurry', Extended Abstracts of the $2019 \mathrm{CHI}$ Conference on Human Factors in Computing Systems - CHI EA '19 (ACM Press 2019) <http://dl.acm.org/citation.cfm?doid=3290607.3310433> accessed 18 June 2019.

${ }^{23}$ Luciano Floridi, 'On Human Dignity as a Foundation for the Right to Privacy' (2016) 29 Philosophy \& Technology 307, 308.

${ }^{24}$ Robert Fay, 'Digital Platforms Require a Global Governance Framework', Models for Platform Governance (CIGI 2019) <https://www.cigionline.org/sites/default/files/documents/Platform-govWEB_VERSION.pdf\#page $=35>$.

${ }^{25}$ Susan Ariel Aaronson, 'Data Is Different, and That's Why the World Needs a New Approach to Governing Cross-Border Data Flows' [2019] Digital Policy, Regulation and Governance.
} 
of competitive markets that would otherwise produce valuable technological innovations. What are markets? What is their role in society? Can they ever be free of regulation? What kinds of processes and actors are relevant in shaping markets?

At their most basic, markets enable the buying and selling of rights through a medium of exchange (most commonly, money). Early market theories have laid the groundwork for thinking through the prospects - and perils - of free markets. Adam Smith, a key contributor to the neoclassical idea of the self-regulating market, termed this the 'invisible hand': the process by which self-interested behaviour, if 'unfettered by regulatory interference', leads to results that benefit the society as a whole. ${ }^{26}$ Friedrich Hayek echoes Smith in arguing for the superiority of a spontaneous market order, but on the grounds of epistemology. ${ }^{27}$ According to Hayek, markets aggregate and express the knowledge of diffused, localised (market) actors. Via the price mechanism, markets are able to disseminate information, channel dispersed resources and fulfil people's localised needs - rendering misguided and oppressive centralised economic planning unnecessary.

Schumpeter emphasised how the competitive struggle forces market actors to take on an entrepreneurial, innovative mentality, continually revolutionising 'the economic structure from within, incessantly destroying the old one, incessantly creating a new one'. ${ }^{28}$ Thus, Schumpeter too saw capitalist markets as having an emergent, energetic dynamism of their own. Already in Hayek, however, it becomes evident that a supposedly self-regulating market requires institutional embedding. ${ }^{29}$ The same holds true today. Markets are neither autonomous nor natural. On the contrary, they are social constructs, and therefore take different forms at different times and in different places. Given the amount of political and regulatory decisions that complex markets presuppose ${ }^{30}$ they raise the question of who benefits from how they are organised.

'Society at large', the aforementioned theorists would have argued. For them, economic liberty represented a morally superior mechanism for coordinating society than the alternatives in sight. Karl Polanyi, who observed first-hand the defects of unfettered markets, offered a powerful counterargument to early market liberalism. He famously stated: 'laissez-faire was planned; planning was not' ${ }^{31}$ Capitalism has the tendency 'to turn elements which exist naturally, and which were not meant to be produced for sale in the market, such as labour, land and money, into tradeable commodities'.32 In this way, the well-being of human and environmental resources becomes intimately interlinked with and subjected to market forces. Expanding marketisation in the service of the profit imperative tends to undermine its own foundations by exploiting natural and human resources alike. In the face of deteriorating livelihoods and environments, citizens organise and governments take action, keeping capitalism in check while simultaneously enabling it to evolve. ${ }^{33}$

${ }^{26}$ Adam Smith, An Inquiry into the Nature and Causes of the Wealth of Nations with a Life of the Author: Also a View of the Doctrine of Smith, Compared with That of the French Economists, with a Method of Facilitating the Study of His Works, from the French of M. Jariner (Thomas Nelson 1843). ${ }^{27}$ FA Hayek, The Road to Serfolom.ll University of Chicago Press (Chicago 1944).

28 Joseph A Schumpeter, Capitalism, Socialism and Democracy (Harper and Brothers 1942).

29 Hayek (n 27).

${ }^{30} \mathrm{Ha}$-Joon Chang, 'Breaking the Mould: An Institutionalist Political Economy Alternative to the Neoliberal Theory of the Market and the State' (2002) 26 Cambridge Journal of Economics 539.

${ }^{31}$ Polanyi (n 8), 147.

32 Polanyi (n 8).

${ }^{33}$ Polanyi (n 8). 
Shoshana Zuboff engages with classic market theorists from Hayek to Polanyi in her analysis of the digital economy. In what she terms 'surveillance capitalism', a handful of companies operating in a relatively free market have amassed near total information. This has created an order where 'our lives are scraped and sold to fund their freedom and our subjugation, their knowledge and our ignorance about what they know' ${ }^{34}$ Surveillance capitalists capture and process personal and sensitive behavioral data. Thus, Zuboff argues that it is first and foremost internet users' private moments and feelings that are being exploited for profit. In consequence, she encourages 'users' to form a Polanyian counter-movement and demand a more just digital economy. However, we contend that markets for data - and their related harms - cannot be reduced to a simple antagonism between super-platforms and their users. They are much more complex. Individuals may suffer unexpected harms related to the trading of even non-personal data, and not only as users, but as labourers, patients, residents or citizens as well. In the following sections, we begin to unpack this complexity.

\subsection{Contemporary work on market processes}

Moving from theoretical work to more empirical research, the sociology of markets (drawing from network theory, organisational studies, institutional theory and science and technology studies (STS)) has been especially influential in demonstrating the social, institutional and material embeddedness of markets. Markets are able to bring into interaction a diverse set of localised actors with different interests and goals, while still holding together and having an order. Fligstein and Calder describe sociology's understanding of markets as 'socially constructed arenas where repeated exchanges occur between buyers and sellers under a set of formal and informal rules governing relations amongst competitors, suppliers and customers'. ${ }^{35}$ This definition gives primacy to social relations and institutions. It should be enriched with research originating from the intersection of STS and economic sociology that emphasises the roles of applied science, technological artefacts and material infrastructures in shaping contemporary markets. Regulatory tools are not external to markets either, but form a part of the interacting whole. Even though socio-technical systems are never stable, once in action, they cannot be totally reversed. They will have weaved too many (social and material) connections to easily disassemble. ${ }^{36}$ Thus, STS research has stressed the importance of the debates taking place around emerging technologies and market arrangements.

There are many (partly related) organising principles for classifying markets - from price relationships, competitive structure or market maturity to their spatial reach. Which one to choose depends largely on one's pragmatic purposes. Antitrust and economics rely on the factors of product substitutability and price, respectively, to determine market boundaries. In consequence, they see data markets as marginal in scope, covering only the markets for actual datasets. While precise, such narrow analytical tools could make the data economy look like a chaotic collection of separate markets, furnished with groups of players which share little in common. We, in contrast, conceptualise the market for data as an assemblage that brings together various kinds of producers, customers, data objects and subjects, analytic practices and labour. This exploratory approach

\footnotetext{
${ }^{34}$ Zuboff (n 11) 498.

${ }^{35}$ Neil Fligstein and Ryan Calder, 'Architecture of Markets' in Robert Scott and Stephan Kosslyn (eds), Emerging Trends in the Social and Behavioral Sciences (John Wiley \& Sons 2015), 1.

${ }^{36}$ Bruno Latour, 'Technology Is Society Made Durable' (1990) 38 The Sociological Review 103.
} 
enables us to better grasp the wider sociomaterial networks of interdependence within which data markets are nested.

How do we begin to approach data markets as a whole? One can start from the relative opacity of the data market to researchers interested in regulation, using 'dark pools' as a point of reference for the challenges of understanding how data is traded and channelled. Scholars have for some time compared the adtech market to financial markets, characterising social media data profiles as a form of derivatives and analysing how the online advertising market produces problems of competition and conflict of interest similar to those seen in equities markets. ${ }^{37}$ Fay has tackled the issue of 'digital stability' in relation to under-regulated regional data markets, ${ }^{38}$ and Aaronson has made the case for global trade rules specific to data. ${ }^{39}$

Work on data's similarity to both financial instruments and tradeable commodities is useful in showing that we do not have to reinvent the wheel in order to regulate trade in data. However, as Aaronson argues, 'data is different' because unlike securities or derivatives, data originates from people,${ }^{40}$ and its trade and reuse has impacts on 'situated, embodied beings' ${ }^{41}$ Rather than assuming that we can govern data the way we govern finance, then, we must distinguish the ways in which the markets for data do and do not behave like financial markets. For example, one key characteristic of the global movement of data is its opacity. The operations of large players in financial markets articulate some features and functions of the data market assemblage, the opacity of which, we argue, is a structural feature. 'Dark pools'42 - private stock markets, whose buy and sell orders are not listed in open order books - constitute a way of trading away from the gaze of regulators and the public. Dark pools widen the epistemic gap between their operators, who have access to virtually all financial information, and the rest. Indeed, even customers themselves are often unaware of the functioning of dark pools and the information contained within them..$^{43}$ Limited facts about transactions are revealed only after they have been executed by the dark pool operator. $^{44}$

Dark pools have strayed from their initial purpose, which was merely to facilitate block trades without causing 'the domino effect that large trades might have on the price of an equity' in a public

\footnotetext{
${ }^{37}$ Adam Arvidsson, 'Facebook and Finance: On the Social Logic of the Derivative' (2016) 33(6) Theory, Culture \& Society 3; Dina Srinivasan, 'Why Google Dominates Advertising Markets' (2020) 24 Stanford Technology Law Review 55.

${ }^{38}$ Robert Fay, 'The World Faces a Turning Point on Data and Al. Will We Learn from the Financial Crisis?' Centre for International Governance Innovation (28 May 2019). $<$ https://www.cigionline.org/articles/world-faces-turning-point-data-and-ai-will-we-learn-financial-crisis> accessed 12 March 2021.

${ }^{39}$ Adam Arvidsson, 'Facebook and Finance: On the Social Logic of the Derivative' (2016) 33 Theory, Culture \& Society 3.

40 Aaronson (n 25).

${ }^{41}$ Julie E Cohen, Configuring the Networked Self: Law, Code, and the Play of Everyday Practice (Yale University Press 2012).

${ }^{42} \mathrm{We}$ acknowledge the problematic connotation of the term 'dark pools'.

${ }^{43}$ Karla Stein, 'SEC.Gov | Market Structure in the 21st Century: Bringing Light to the Dark' (30 September 2015) <https://www.sec.gov/news/speech/stein-market-structure.html> accessed 9 June 2021.

44 Teresa W Carey, 'Shedding New Light on Dark Pools | Barron's' (Wall Street Journal, 29 June

2009) <https://www.barrons.com/articles/SB124605592600863381?tesla=y> accessed 9 June 2021.
} 
exchange. ${ }^{45}$ In 2017, the trading volume of these opaque enclosures exceeded that of the New York Stock Exchange. ${ }^{46}$ Operators of dark pools have begun to deviate from their roles as 'objective' intermediaries by taking part in the transactions themselves, which gives rise to conflicts of interest. ${ }^{47}$ Furthermore, they have also been found to secretly favor some customers over others. In addition to their official operations, dark pools may enable operators to carry out illegitimate trades with their preferred investors. ${ }^{48} \mathrm{~A}$ final matter of concern is the correlation between the growth of dark pools and the increased prevalence of risky, low-quality and speculative derivatives. ${ }^{49}$

Data markets share a similar trajectory of covert expansion. Since their advent in the 1990s, they have developed relatively free of regulation, largely without public awareness, ${ }^{50}$ and with market actors continuously diversifying their data sources. ${ }^{51}$ Like dark pools, data markets combine organisations, data streams, hardware and software into opaque, rapidly transacting global assemblages. Value is often extracted by means of abstracting 'data derivatives' from click streams and other behavioural traces, ${ }^{52}$ and exchanging these profiles for economic gain. Similarly to financial predictions, personal futures are performative, steering observed processes into their inferred direction. While these predictions intervene in human lives and societal processes, debating their legitimacy is difficult under the prevailing conditions of opaqueness that characterises the trading and processing of data for commercial ends. Figure 1 below shows the types of personal data offered by one aggregator, clearly targeted towards advertisers.

\footnotetext{
45 Jennifer Conrad, Kevin Johnson and Sunil Wahal, 'Institutional Trading and Alternative Trading Systems' (2003) 70 Journal of Financial Economics 99.

${ }^{46}$ Sam Mamudi and Annie Massa, 'Dark Pools' Bloomberg.com

<https://www.bloomberg.com/quicktake/dark-pools> accessed 9 June 2021.

47 Stein (n 43).

${ }^{48}$ Luis Aguilar, 'SEC.Gov | Shedding Light on Dark Pools' (2015)

<https://www.sec.gov/news/statement/shedding-light-on-dark-pools.html> accessed 9 June 2021.

${ }^{49}$ Saskia Sassen, 'Predatory Formations Dressed in Wall Street Suits and Algorithmic Math' (2017)

22 Science, Technology and Society 6.

50 Leanne Roderick, 'Discipline and Power in the Digital Age: The Case of the US Consumer Data

Broker Industry' (2014) 40 Critical Sociology 729.

51 Jonathan A Obar, 'Big Data and The Phantom Public: Walter Lippmann and the Fallacy of Data Privacy Self-Management' (2015) 2 Big Data \& Society 2053951715608876.

52 Louise Amoore, 'Data Derivatives: On the Emergence of a Security Risk Calculus for Our Times' (2011) 28 Theory, Culture \& Society 24.
} 


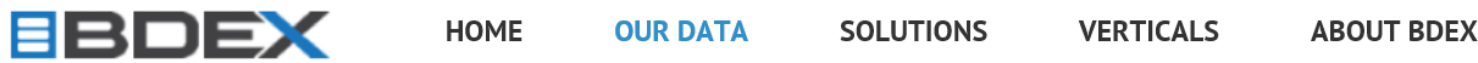

\begin{tabular}{|c|c|c|c|}
\hline \multicolumn{2}{|c|}{317 Available Industries } & \multicolumn{2}{|c|}{8 Taxonomies } \\
\hline Industry Name & Count & Taxonomy Name & Count \\
\hline Persona\Employment & $4,935,155,643$ & Annual Income & $278,821,337$ \\
\hline Persona\Family & $297,798,949$ & Audience Class & $21,681,176,290$ \\
\hline Persona|Finances & $22,209,000,040$ & Credit Score & $32,115,971$ \\
\hline Persona\Home & $15,605,951,818$ & Credit Score Over 600 & $32,115,971$ \\
\hline Persona\Religion & $154,422,485$ & Dataset Class & $22,209,000,040$ \\
\hline Recreation \Audio & 1,206 & Low Credit Score & $32,115,971$ \\
\hline Recreation $\backslash$ Autos & $1,375,577,327$ & Net Asset Value & $139,792,946$ \\
\hline Recreation\Aviation & 67,020 & Philanthropic Donar & $77,093,494$ \\
\hline Recreation\Birding & 1,673 & & \\
\hline Recreation\Boating & $23,892,726$ & & \\
\hline Recreation $\backslash$ Camping & $75,706,024$ & & \\
\hline Recreation\Climbing & 29,694 & & \\
\hline Recreation\Collecting & 1,542 & & \\
\hline
\end{tabular}

Figure 1. BDEX Finance data

Dark pools are a peripheral but important feature of the stock market. In contrast, they seem to be a basic functional modus operandi for the data market, where they describe trading both by large firms and by smaller players. Dark pools take different forms: some of them are independent, while others are run by well-known banks and public exchanges; some trade automatically, while in others traders are able to interact with orders (which is called 'negotiation'); some are interconnected, routing orders to other private exchanges. Similar heterogeneity exists in data markets as well. While Google and Facebook act as fully automated, 'high-frequency' exchanges where customers can 'rent' profiles to advertise to, there are also other market players who are engaged in very different forms of trading, such as location data provision or brokers' sale of profiles (see Fig. 1). Such trading happens directly between companies in a way that is essentially opaque to regulators and the public.

This opacity is an important starting point for a regulatory perspective because it suggests that some tools for transparency might be borrowed from financial regulation. However, it does not tell us what challenges face regulators once that veil is penetrated. In the next section, we draw on industry perspectives to sketch out how market dynamics reconfigure data assemblages into distinct types of exchanges, business models and cooperative and competitive structures.

\section{Perspectives on data markets}

Why speak of data markets in general, rather than revert to more limited, and thus precise, market definitions? Our contention is that data is the key resource for the goods exchanged within many contemporary markets, from markets for credit scoring to markets for agricultural data, amongst 
countless other types. Importantly, the analytic outputs and services that are traded within these markets (e.g. predictive algorithms or automated control systems) do not merely describe the world 'out there', but facilitate active intervention in it, be it for the purposes of optimisation, risk reduction or economic gain. Markets for data are thus always feedback-looped with their surroundings. They have human and societal impacts - whether or not personally identifiable data is at stake. This is why we approach data markets as heterogeneous assemblages instead of conceptualising them from the point of view of pre-existing regulatory tools such as data protection that are more narrow in their scope.

In the previous section, we argued that some functionality in trading in the data market seems to replicate the operations of private trading venues known as dark pools. In this section, we take a more systematic look at the data market nexus. We draw first directly from business management. This perspective on data reflects that information on the data market is emerging from the industry side, partly in response to regulatory challenges. Then we turn to the competition approach, which is another powerful - yet in the social studies of data, often overlooked - way of taking stock of relevant market actors and processes. By these means, we are able to identify distinct types of data exchanges as well as connection points between different actors and sectors at different stages of the production chain. Furthermore, by focusing on (non)competition, we tease out the general power (im)balances that characterise markets for data.

\subsection{The data 'value chain'}

A value chain analysis breaks the production of data commodities and services down into subsets of activities, which take the prior stage's output as their input. It covers the process from generating, capturing and cleaning data to processing them, finally creating end user-friendly analytics and data products. We are critical towards its discursive framing - in existing literature, commercial data assemblages are often seen as exploitative and value-extracting rather than democratising the value of data. ${ }^{53}$ However, it does provide a starting point for mapping out flows of data, software, services and capital within data markets.

\footnotetext{
${ }^{53}$ Nick Couldry and Ulises A Mejias, 'Data Colonialism: Rethinking Big Data's Relation to the Contemporary Subject' (2019) 20 Television \& New Media 336; Laura Mann, 'Left to Other Peoples' Devices? A Political Economy Perspective on the Big Data Revolution in Development: A Political Economy of Big Data in Development' (2018) 49 Development and Change 3.
} 


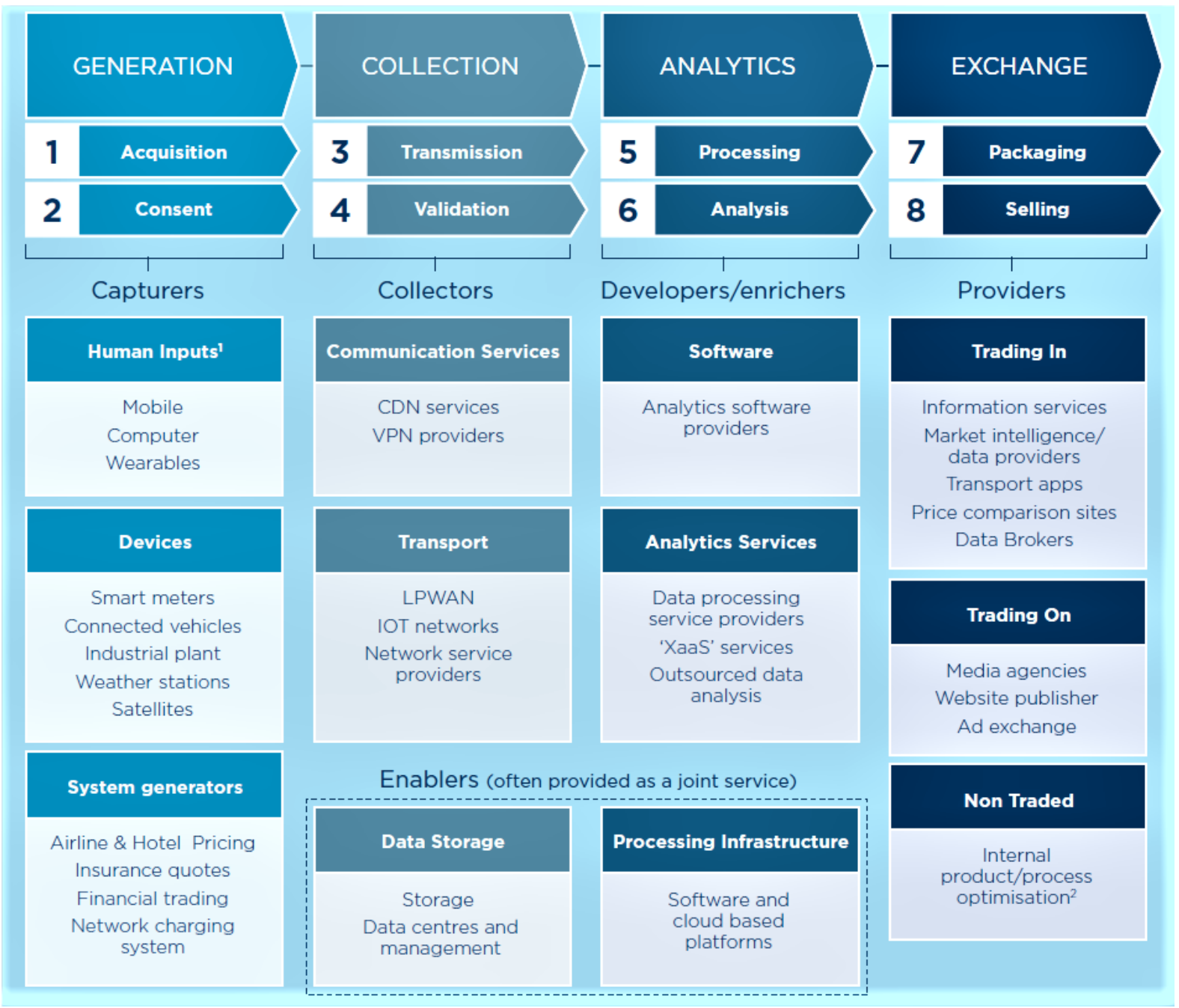

Figure 2. The data value chain ${ }^{54}$

The figure above illustrates a view of the data value chain from the perspective of the GSMA, a trade body for the mobile industry. It applies as much to personal and anonymised data as to industry data. While extensive, it is only a small piece of the whole, visualising the commercial, US and EU elements of the data market. To reach the global and cross-sectoral level, we might want to include both other analytical actors such as academia, as well as other systematically data-producing sectors such as health, agriculture and humanitarian organisations.

According to the GSMA view of the data value chain, it contains four distinct phases. The generation stage involves data originating from both humans and machines. The collection stage covers both the transmission of data through networks and the validation of data. At the validation stage, a datum is identified and stored with all related data to a data architecture that enables fast access and processing. At the analysis stage, data is mined - i.e. processed by means of mathematical algorithms - in order to find patterns. Analysis is required to make sense of and form hypotheses

54 GSMA, 'The Data Value Chain' (GSMA 2018) <https://www.gsma.com/publicpolicy/resources/thedata-value-chain> accessed 9 June 2021. 
based on what are initially more or less random correlations, and transform them into actionable knowledge..$^{55}$ Analytic outputs, in a process such as that shown above, can be fairly simple, as in the case of customer lists or sentiment analysis, or advanced, such as when user-generated data is harnessed to make predictions about, and act upon, other users. ${ }^{56}$ In line with this, Bagnoli argues for a different taxonomy of processes, segmenting the data chain into generation, capture, storage, analytics and use. ${ }^{57}$ Including 'use' demands a thicker conception of the market as feeding into other systems which then also have social impacts.

The implication for regulation is that any approach which refers to 'data' as a unitary object is likely not only to miss many relevant types of datafied process, but also to invisibilise the ways in which data has impacts on people. Thus, for example, proposals for fiduciary trusts have potential to govern data generated by commercial platforms, ${ }^{58}$ personal data store ${ }^{59}$ to generate data from health providers, banks, and other consumer-facing services, and 'data altruism intermediaries' to govern health data in a research context. The variety subsumed under 'the data market', though, means that many regulatory discussions occur at cross-purposes, with one party thinking about data people are aware of generating, such as social media or health data, and another thinking about geographic sensing data or agricultural data, which may be bundled very differently in terms of their ownership and the interests involved. ${ }^{60}$

\subsection{Types of exchanges for data}

When the final data product is used in-house or exchanged, the value accumulated throughout the prior stages of the chain is realised. ${ }^{61}$ In-house, data can be used to increase the efficiency of production facilities or gain insights on pre-existing customers. As noted, we still know fairly little about the exchanges that exist for data. The GSMA identifies two distinct types. The first trade on insights. In other words, exchanges of this type provide data-based services and analytics to other organisations and companies without trading the underlying data themselves. The most prominent example are so-called online ad exchanges. When accessing a website, inferred information about the user is sent to an auction, where the highest bidder wins the opportunity to advertise to her. All this happens before the website loads. ${ }^{62}$

\footnotetext{
${ }^{55}$ However, not all data value chains include data mining or analysis.

${ }^{56}$ Amoore (n 52).

57 Vicente Bagnoli, 'The Big Data Relevant Market As a Tool for a Case by Case Analysis at the Digital Economy: Could the EU Decision at Facebook/WhatsApp Merger Have Been Different?' (Social Science Research Network 2017) SSRN Scholarly Paper ID 3064795 <https://papers.ssrn.com/abstract=3064795> accessed 9 June 2021.

58 Sean McDonald, 'The Fiduciary Supply Chain', Models for Platform Governance (CIGI 2019).

59 Tuukka Lehtiniemi and Jesse Haapoja, 'Data Agency at Stake: MyData Activism and Alternative Frames of Equal Participation' (2020) 22 new media \& society 87.

60 Madeleine Fairbairn and Zenia Kish, "'A Poverty of Data"?: Exporting the Digital Revolution to Farmers in the Global South', The Nature of Data: Infrastructures, Environments, Politics (University of Nebraska Press).

${ }^{61}$ GSMA (n 54).

62 'Buy, Buy, Baby' [2014] The Economist <https://www.economist.com/specialreport/2014/09/11/buy-buy-baby> accessed 9 June 2021.
} 
The second type of exchanges trade in data. More commonly known as data brokers, these companies and business units earn [their] primary revenue by supplying data or inferences about people gathered mainly from sources other than the data subjects themselves. ${ }^{63}$

Data brokers' products include raw, curated and inferred datasets. ${ }^{64}$ For example, share price information is not 'raw' data, but 'the output of a series of analytic steps that derive the price from a set of discrete transactions using an algorithm'. ${ }^{65}$ The trade in raw data makes up only a small fraction of data brokers' activity (approx. 4\% in the EU, according to 2018 estimates). ${ }^{66}$ Monetising unprocessed raw data is difficult for two main reasons. First, the value of data cannot be known beforehand, but becomes revealed only through data preparation, mining and analysis. ${ }^{67}$ Second, raw data often contains identifiable information. Trading it thus raises obvious privacy concerns and faces regulatory barriers. However, there is a point to be made that even the brokerage of processed, deidentified datasets may violate the data subject's privacy and dignity by way of discretely moving data about her from one informational setting - with its specific conventions and rules - to another, perhaps less regulated one. Furthermore, when data is aggregated, creatively recombined and matched, the granularity of the data increases, threatening anonymisation.

While companies are typically active in multiple stages of the value chain, many of them routinely outsource storage and analytics, which are expensive to carry out in-house, to external data processors operating under a contract. Noteworthy public-private partnerships have emerged in these stages of the chain, with tech giants creating cloud solutions for governmental data operations. The value chain is rife with linkages to other industries that feed data markets' appetite for data-generating apparatus and applications, efficient data infrastructures and powerful analytics. While the data value chains of different sectors are for the most part separate, they can still intersect and cross-fertilise by way of outsourcing to the same subcontractors or through the transfer of models. As an example of the latter, PredPol, the market leader in predictive policing software, is based on mathematical models used originally by academics to predict seismic activity. ${ }^{68}$

The value chain approach begins to tease out some of the most prominent business models that have developed around the exchange of data and also points to linkages between them. It allows us to explore flows of information and capital within the data market assemblage that are noteworthy from a regulatory as well as a political economy perspective. Next, we turn to the competition approach, to better understand the configurations of power at play within these markets.

\subsection{The state of data governance}

${ }^{63}$ Rieke and others (n 19) 4.

64 GSMA (n 54).

65 GSMA (n 54).

66 GSMA (n 54).

${ }^{67}$ Sveta Milyaeva and Daniel Neyland, 'Market Innovation as Framing, Productive Friction and

Bricolage: An Exploration of the Personal Data Market' (2016) 9 Journal of Cultural Economy 229.

${ }^{68}$ Ellen Huet, 'Server And Protect: Predictive Policing Firm PredPol Promises To Map Crime Before It Happens' (Forbes) <https://www.forbes.com/sites/ellenhuet/2015/02/11/predpol-predictive-policing/> accessed 9 June 2021. 
Understanding the processes by which data extraction and data-driven insights are transformed into a commodity ${ }^{69}$ or a subject of value are important for our understanding of the scope and the workings of a data market. These processes are also increasingly the focus of public interest and scrutiny, but, as noted, existing data governance regimes seem unable to bridge the gap 'between data's de jure status as the subject of consumer rights and its de facto status as quasi-capital' ${ }^{70}$ Grasping this tension is thus one of the necessary steps towards conceptualising data markets; for this, the regulatory frameworks that currently attempt to grapple with the nature of data and how it gains value need to be explored. These frameworks revolve around distinct, sometimes overlapping or opposing, policy imperatives and demonstrate the actors, interests and objectives involved. They are discussed below and can be categorised into two visions: (i) rights-based approaches, and (ii) public and private interest-based approaches. Our focus on the EU case here complements the primarily US-based inquiry of Viljoen.

\subsubsection{Focus on (individual) rights: privacy and data protection}

First, the privacy perspective is based on protecting the data subject's dignity or autonomy. ${ }^{71}$ Regulatory approaches when it comes to personal data has, since the 1980 s been focused on protecting the fundamental rights of privacy and data protection. ${ }^{72}$ Currently, in the EU, at least, the General Data Protection Regulation (GDPR) is considered to be the cornerstone of data governance. ${ }^{73}$ The GDPR was adopted with a view to harmonize the (personal) data protection rules across the EU. The approach of the GDPR is based on informational self-determination, underpinned by 3 core principles of notice, consent, and purpose limitation. ${ }^{74}$ Under this regime, "/n/atural persons should have control of their own personal data"75 and thus be more empowered when it comes to data processing practices. ${ }^{76}$ The GDPR reinforced and/or introduced new data subject rights, set forth compliance mechanisms, and means for consistent application of data protection rules throughout the EU. ${ }^{77}$ As such, the GDPR "reflects a liberal, individualistic ideology of privacy". ${ }^{78}$ With (individual) privacy as "the dominant form of discussing and regulating the problems associated with data collection and processing", ${ }^{79}$ other costs of data-driven practices - like price discrimination, behavioral manipulation, and social exclusion - are overlooked ${ }^{80}$ and the business model associated with them unchallenged ${ }^{81}$. In this sense, and because of its insistence on the

${ }^{69}$ Salome Viljoen, 'Democratic Data: A Relational Theory For Data Governance' [2020] Available at SSRN 3727562.

70 Viljoen (n 69) 2.

71 Viljoen (n 69) 5.

72 Palka in Roxana Vatanparast, 'Designed to Serve Mankind? The Politics of the GDPR as a Global Standard and the Limits of Privacy' (2020) 80 The Politics of the GDPR as a Global Standard and the Limits of Privacy (December 1, 2020) 819, 5-7.

${ }^{73}$ Luca Marelli, Elisa Lievevrouw and Ine Van Hoyweghen, 'Fit for Purpose? The GDPR and the Governance of European Digital Health' (2020) 41 Policy studies 447, 449.

${ }^{74}$ Elettra Bietti, 'Consent as a Free Pass: Platform Power and the Limits of the Informational Turn'.

${ }^{75}$ General Data Protection Regulation, Recital 7

76 Iris van Ooijen and Helena U Vrabec, 'Does the GDPR Enhance Consumers' Control over Personal Data? An Analysis from a Behavioural Perspective' (2019) 42 Journal of consumer policy 91.

77 Bietti (n 74) 337-8.

78 Vatanparast (n 72) 7.

79 Vatanparast (n 72) 13-14.

80 Palka in Vatanparast (n 72) 15.

81 Cohen in Vatanparast (n 72) 16. 
individual control aspect, as well as the "volume and manner of personal data processing", ${ }^{82}$ the GDPR has been critiqued for overlooking "the power asymmetries and information externalities that make individual-centric decision-making objectionable", ${ }^{83}$ as consumers find themselves in a vulnerable position and unable to "make well-informed decisions about the use of their data, or to invoke their rights" ${ }^{84}$ Further, the fact that much of the value from data comes from not only gaining insights about an individual based on their data, but also from inferences made on the data about others, the individual control aspect "fails to account for the relational qualities of data processing and the collective interests they touch upon". ${ }^{85}$

\subsubsection{Focus on incentives: policy and economic considerations of data}

Privacy and data protection are firmly based in the rights narrative. At the same time, however, the GDPR itself is "premised on the objective to balance the protection of individual privacy and the promotion of a thriving European data economy", 86 thus serving both as a tool for protection of fundamental rights and simultaneously as a tool for governing economic activity and the free movement of (personal) data. It is through unifying the levels of protection that potential barriers to trade are prevented. ${ }^{87}$ In this light, 28 digital single market legislative proposals designed to create a digital single market have been approved by the EU since $2014 .{ }^{88}$ These initiatives deal with data more or less directly and ultimately shape the way data can be shared and/or traded and by whom. Some of these are briefly touched upon below; by no means is this intended to be a comprehensive overview, more so an illustration of current developments that will provide new rules around data and ways in which it might or might not be shared and traded and supporting new intermediaries in the data value chain. Further, data protection laws have the effect of certifying countries as having adequate data protection provisions, making it possible for them to trade data with other countries which have passed data protection rules (e.g. through 'adequacy' decisions). By 2019 there were 132 data protection laws in existence globally, with many more under discussion. ${ }^{89}$ Beyond individual rights, it is thus also important to discuss the imperatives that define the rules concerning the sharing and/or use of (valuable) data, both personal and non-personal and both held by private and public sectors, as they are also relevant for creating the market and regulating the behaviours of

\footnotetext{
82 Peter J van de Waerdt, 'Information Asymmetries: Recognizing the Limits of the GDPR on the DataDriven Market' (2020) 38 Computer Law \& Security Review 105436, 2.

${ }^{83}$ Bietti (n 74) 339.

${ }^{84}$ van de Waerdt (n 82) 2.

${ }^{85}$ Vatanparast (n 72); Viljoen (n 69).

${ }^{86}$ Marelli, Lievevrouw and Van Hoyweghen (n 73) 447; Regulation (EU) 2016/679 of the European Parliament and of the Council of 27 April 2016 - on the protection of natural persons with regard to the processing of personal data and on the free movement of such data, and repealing Directive 95/46/EC (General Data Protection Regulation) 201688.

87 Inge Graef, Raphaël Gellert and Martin Husovec, 'Towards a Holistic Regulatory Approach for the European Data Economy: Why the Illusive Notion of Non-Personal Data Is Counterproductive to Data Innovation' 4; Vatanparast (n 72).

${ }^{88}$ European Commission, 'European Data Strategy' (European Commission - European Commission) $<$ https://ec.europa.eu/info/strategy/priorities-2019-2024/europe-fit-digital-age/european-datastrategy_en> accessed 9 June 2021.

${ }^{89}$ Graham Greenleaf, 'Global Data Privacy Laws 2019: 132 National Laws \& Many Bills' (Social Science Research Network 2019) SSRN Scholarly Paper ID 3381593 <https://papers.ssrn.com/abstract=3381593> accessed 9 June 2021.
} 
those therein. They range from achieving important societal and economic objectives to establishing competitive advantage and are briefly discussed below.

\subsubsection{Data in public policy narratives}

Data-driven (or digital) economy in the EU is stimulated through different initiatives and policy actions that have been launched in the past couple years. In this, data features as means to spur the development of "new, innovative services for which data forms a valuable input" 90 and "access to data and the ability to use it /are/ essential for innovation and growth". ${ }^{91}$ Beyond a flourishing digital economy, data is also considered as a transformative force that will enable better decision-making in both public and private sectors and bring "enormous benefits for citizens, for example through improved personalised medicine, new mobility and through its contribution to the European Green Deal" (A European strategy for data, 2020).$^{92}$ The objective of this strategy is to create a single market for data, in order to capture its benefits; a common market based on "fair, practical, and clear" rules and respecting the applicable protections. This will be achieved by relying on data interoperability and portability to break the 'silos' and facilitate choice and control. ${ }^{93}$

The many (EU) initiatives proposed or still expected focus on different types of data and various actors involved in data-sharing practices. There is the Regulation on the free flow of non-personal data of May 2019 formally established the freedom for EU countries to trade internationally in nonpersonal data. The intention is to extend the principle of free movement of data to non-personal data as well, ${ }^{94}$ however - as pointed out -, the distinction between personal and non-personal data is increasingly difficult to maintain, due to issues of re-identification, contextual specificities, and hyper-connectedness. ${ }^{95}$ Another initiative is the proposal for an EU Data Governance Act, ${ }^{96}$ which intends to encourage greater sharing of data within and between sectors and among businesses, and increase trust in data sharing. With the objective of fostering the availability of data, the following situations are addressed: re-use of public sector data, data sharing among businesses, "against remuneration in any form", sharing personal data with the help of "personal data-sharing intermediary", and allowing data use on altruistic grounds. ${ }^{97}$ Part of the previously mentioned European Strategy for Data, Data Governance Act provides "a framework that leverages access to publicly held data", yet arguably ignores the political implications of (realization of digital rights

\footnotetext{
90 Graef, Gellert and Husovec (n 87) 2.

${ }^{91}$ European Commission, 'European Data Strategy' (n 88).

92 Communication from the Commission to the European Parliament, the Council, the European Economic and Social Committee, and the Committee of the Regions on A European strategy for data. $\mathrm{COM} / 2020 / 66$ final

93 Ibid.

94 Graef, Gellert and Husovec (n 87) 1-5.

95 Graef, Gellert and Husovec (n 87) 5-9.

${ }^{96}$ European Commission, 'Proposal for a Regulation of the European Parliament and of the Council on European Data Governance (Data Governance Act) COM(2020) 767 Final' <https://eurlex.europa.eu/legal-content/EN/TXT/PDF/?uri=CELEX:52020PC0767> accessed 6 September 2021. ${ }^{97}$ European Commission, 'Proposal for a Regulation of the European Parliament and of the Council on European Data Governance (Data Governance Act) COM(2020) 767 Final' (n 96).
} 
through) market integration and the data sharing practices ${ }^{98}$ Additional measures regarding rights on access and use of data will be outlined in the Data Act, which is expected in 2021.

Beyond these legal frameworks there are others which fill in gaps, provide exceptions, and shape the market in less visible ways. These include the laws governing the use of data by law enforcement, such as the EU Police Directive of 2016, or rules around how data may be accessed by intelligence services from commercial platforms, such as those in the US post-9/11 Patriot Act or the UK 2016 Investigatory Powers Act. They also include payment and banking legislation, including the EU's PSD2 Directive which creates a market for people's banking transaction information, and local-level contracts and procurement around smart city technologies, such as the adoption of Google's payment systems for public-sector transport payments when the company provides transport optimisation systems to cities around the world. Finally, initiatives with the mission to open data on a non-profit basis can also be seen as influencing what data becomes available: governmental open data initiatives (see also above) often cite stimulating business as one central aim, and academic research data can similarly be traded and used in ways that create value for particular actors - one example being the use of an open US academic dataset of facial images by the Chinese to train facial recognition algorithms for law enforcement and security. ${ }^{99}$

A number of other regulatory measures is currently under discussion, striving towards a re-definition of the governance of digital markets more broadly. These aim to devise a comprehensive set of harmonised rules and responsibilities to govern (big and smaller) digital platforms and services, their business models, and use of data, namely to create a safer digital space and establish fair and open digital markets. ${ }^{100}$ This could importantly affect how data is shared and valued. The proposals, among others, prescribe that large online platforms will, for example have to allow their business users to access the data they generate, ${ }^{101}$ possibly leading to diversifications in data trade.

\subsubsection{Data and competition in and for the markets}

What can also be observed from initiatives mapped above is the focus on establishing a market that would act as a level playing field, by focusing for instance on interoperability and portability of data. This brings us to the dimension of the functioning of the markets and the role and value of data as an economic incentive or a market parameter therein. As noted, access to data is increasingly becoming a key competitive advantage for companies to better understand their users or customers, improve or develop new products, and "more advantageously price goods /or/ services". ${ }^{102}$ From the

\footnotetext{
98 Sean McDonald, 'A Novel, European Act of Data Governance' (Centre for International Governance Innovation, 15 December 2020) <https://www.cigionline.org/articles/novel-european-act-datagovernance/> accessed 9 June 2021.

99 Jake Satisky, 'A Duke Study Recorded Thousands of Students' Faces. Now They're Being Used All over the World' (Duke University Chronicle, 6 December 2019)

$<$ https://www.dukechronicle.com/article/2019/06/duke-university-facial-recognition-data-set-studysurveillance-video-students-china-uyghur> accessed 9 June 2021.

100 European Commission, 'The Digital Services Act Package | Shaping Europe's Digital Future'

<https://digital-strategy.ec.europa.eu/en/policies/digital-services-act-package> accessed 9 June 2021. 101 European Commission, 'The Digital Markets Act: Ensuring Fair and Open Digital Markets'

(European Commission - European Commission) <https://ec.europa.eu/info/strategy/priorities-20192024/europe-fit-digital-age/digital-markets-act-ensuring-fair-and-open-digital-markets_en $>$ accessed 9 June 2021.

102 Viljoen (n 69) 4.
} 
economics perspective, data can be considered a product in itself, an asset that could lead to market power, an input for another product or commercially irrelevant. ${ }^{103}$ In the recent past, competition enforcement agencies have been no stranger to cases concerning data, but some contentious points of debate remain and have been addressed in the literature. Moreover, adapting to the digital economy is also high on the agenda of policy-makers that have issued many reports and collected opinions on how best to do that. ${ }^{104}$

Competition law scholars and policy actors are increasingly occupied with ways to attribute value to data in the digital market and the competitive advantage it grants to market players. ${ }^{105}$ Some see data as ubiquitous and readily available, others point out that this is not always the case and some types of data are difficult to collect, access, replicate and process. ${ }^{106}$ or that (only) some data is essential to compete. ${ }^{107}$ It has been acknowledged by the Commissioner that "data doesn't automatically equal power" ${ }^{\prime 108}$ control over big data "isn't such a big issue, if others can easily get hold of the same information" ${ }^{109}$ Still, data collection, pooling, and analysis can lead to the creation of market power, especially when datasets are combined from multiple sources. ${ }^{110}$ This can adversely impact competitive market dynamics, meaning that big data is becoming a key parameter of competition, ${ }^{111}$ especially in digital markets where companies often derive value from data "far

${ }^{103}$ Salvatore de Vita and Eleonora Ocello, 'Apple/Shazam: A Remix of Your Favourite Tunes of Data Issues in Merger Control. Competition Merger Brief 1/2019' 1

$<$ https://ec.europa.eu/competition/publications/cmb/2019/kdal19001enn.pdf>; Greg Sivinski, Alex Okuliar and Lars Kjolbye, 'Is Big Data a Big Deal? A Competition Law Approach to Big Data' (2017) 13 European Competition Journal 199, 200-1.

${ }^{104}$ For an overview, see: Viktoria HSE Robertson, 'Antitrust Law and Digital Markets: A Guide to the European Competition Law Experience in the Digital Economy' (Social Science Research Network 2020) SSRN Scholarly Paper ID 3631002 <https://papers.ssrn.com/abstract=3631002> accessed 9 June 2021.

${ }^{105}$ Ariel Ezrachi and Viktoria HSE Robertson, 'Competition, Market Power and Third-Party Tracking' (2019) 42 World Competition 6; Inge Graef, 'Market Definition and Market Power in Data: The Case of Online Platforms' (2015) 38 World Competition.

106 Xavier Boutin and Georg Clemens, 'Defining'Big Data'in Antitrust' [2017] Comptition Policy International: Antitrust Chronicle 22; Marixenia Davilla, 'Is Big Data a Different Kind of Animal? The Treatment of Big Data under the EU Competition Rules' (2017) 8 Journal of European Competition Law \& Practice 370; Sivinski, Okuliar and Kjolbye (n 103).

107 Margrethe Vestager, 'Making the Data Revolution Work for Us | European Commission' (Cambridge Mackenzie Stuart Lecture, 2 April 2019) <https://wayback.archive-

it.org/12090/20191129203859/https://ec.europa.eu/commission/commissioners/2014-

2019/vestager/announcements/making-data-revolution-work-us_en> accessed 9 June 2021.

108 Margrethe Vestager, 'Competition in a Big Data World | European Commission' (DLD 16, Munich, 17 January 2016) <https://wayback.archive-

it.org/12090/20191129204050/https://ec.europa.eu/commission/commissioners/2014-

2019/vestager/announcements/competition-big-data-world_en> accessed 9 June 2021.

109 Margrethe Vestager, 'Fair Markets in a Digital World | European Commission' (Danish Competition and Consumer Authority, Copenhagen, 3 September 2018) <https://wayback.archiveit.org/12090/20191129214609/https://ec.europa.eu/commission/commissioners/20142019/vestager/announcements/fair-markets-digital-world_en> accessed 9 June 2021. 110 Ezrachi and Robertson (n 105) 4.

111 'Big Data: Bringing Competition Policy to the Digital Era - OECD' 9

<https://www.oecd.org/daf/competition/big-data-bringing-competition-policy-to-the-digital-era.htm> accessed 9 June 2021. 
beyond initial purposes for which the data has been collected" ${ }^{112}$ Market power and better access to data might, on the other hand, be linked to more successful product innovation. ${ }^{113}$

In enforcement, data-related issues are usually looked at as a part of company's activity or functionalities offered. ${ }^{114}$ In Microsoft/Linkedin merger, the Commission however also looked into a hypothetical market for the supply of datasets as such (see also the Apple/Shazam merger in Zingales). ${ }^{115}$ As regards competition concerns, competition authorities so far looked at whether data accumulation and use would have anticompetitive effects, namely the foreclosure of competitors with no access to data (i.e. input) or lacking an option to replicate the data advantage and direct harm to consumers or innovation. ${ }^{116}$ The enforcer looked, for instance in the Google/Doubleclick and Facebook/Whatsapp mergers, to see whether a company's market position could be strengthened in the online advertising market by accessing data of the acquired entity and improving the accuracy of targeted ads, hence excluding competitors, but such concerns were dismissed as large amounts of data would be still available online anyway. In the decision concerning Apple/Shazam, the Commission analysed whether Apple would after merger have insights into information on competing apps. Further, the Commission among others developed "a methodology to benchmark different databases available in the market"; specifically, the focus was on types of data, the speed and volume of collected data, and economic relevance to assess "commercial and thus competitive relevance of large datasets" as an input, ${ }^{117}$ demonstrating the evolution of the enforcement approach.

When it comes to personal data in particular, the competition can also interact with data protection rules. Norman et al., ${ }^{118}$ for example, explore the conditions under which excessive selling of consumer data takes place and investigate whether a self-regulated market with transparent privacy policies would lead to an efficient market outcome. The data protection rules could also act as a barrier to data collection and processing practices. ${ }^{119}$ The role of privacy under data protection law is, however, a topic of fierce debates in the literature. ${ }^{120}$ The European Commission has continuously argued, as for example in its decision on Facebook/WhatsApp merger, that privacy-related concerns do not fall under the scope of competition law; however, it has since recognised that data privacy (i.e. a non-price consideration) can be "an important parameter of competition" to be taken into

112 Pamela Jones Harbour and Tara Isa Koslove, 'Section 2 in a Web 2.0 World: An Expanded Vision of Relevant Product Markets' (2009) 76 Antitrust LJ 769, 773.

${ }^{113}$ Reinhold Kesler, Michael Kummer and Patrick Schulte, 'User Data, Market Power and Innovation in Online Markets: Evidence from the Mobile App Industry' [2017] Industry and Innovation Journal 2. 114 Graef (n 105) 489-90.

115 Nicolo Zingales, 'Apple/Shazam: Data Is Power, But Not A Problem Here' [2018] CPI EU News 1.

${ }^{116}$ Anca D Chirita, 'Data-Driven Mergers under EU Competition Law' [2018] The Future of Commercial Law: Ways Forward for Harmonisation,(eds) J Linarelli \& O Akseli (1st ed, Oxford, Hart Publishing, 2019) 150, 164-8; Ezrachi and Robertson (n 98).

117 de Vita and Ocello (n 103) 3-4.

118 George Norman and others, 'Competition and Consumer Data: The Good, the Bad, and the Ugly' (2016) 70 Research in Economics 752.

119 Chirita (n 116) 161-2.

${ }^{120}$ Francisco Costa-Cabral and Orla Lynskey, 'Family Ties: The Intersection between Data Protection and Competition in EU Law' (2017) 54 Common Market Law Review 11; Viktoria HSE Robertson, 'Excessive Data Collection: Privacy Considerations and Abuse of Dominance in the Era of Big Data' (2020) 57 Common Market Law Review. 
account in competition assessment ${ }^{121}$ and an element of product quality and choice, ${ }^{122}$ as acknowledged in the decision on the Microsoft/LinkedIn merger. Lastly, the enforcer has also acknowledged that data can act as a currency where the product itself is offered for free ${ }^{123}$ as evident for instance from the Google Shopping decision. In relation to data protection and in particular concerning consent to platform's terms and conditions, the German Facebook decision on abuse of market power is relevant as well; the German competition authority forbad Facebook "to force its users to agree to the practically unrestricted collection and assigning of non-Facebook data to their Facebook user accounts". ${ }^{124}$ The case is currently under appeal; the Higher Regional Court in Duesseldorf has just announced that the question whether Facebook is indeed abusing its dominant position was referred to the Court of Justice of the European Union, ${ }^{125}$ which will provide some valuable EU-level guidance.

The regimes briefly touched upon above demonstrate the different ways data is valued, as well as indicate the complexities of dealing with data along the value chains. ${ }^{126}$ On their own, these frameworks give us only a limited view on what data (market) could be. This patchwork of laws, regulations, contracts, and commons has the effect of building a framework - national and international - on which various practices of trading and extracting value from data can be based. Taken together, these frameworks can point to the emerging contours and principles of data exchanges. They are also helpful in understanding the entanglements of data and various narratives and implications to be considered by the regulators of the data markets. These frameworks are still evolving and do not currently capture enough of the landscape of data markets (as suggested by the breadth of the GSMA's taxonomy ${ }^{127}$ ) to be termed meaningful governance. We therefore look next at how law and regulation might attempt to get more traction on the data market: what sorts of problems need a response and what the tools might be for doing so.

\section{Regulating the data market}

The data market has been described as a lawless space where corporate actors are uncontrolled and totalitarianism competes with capitalism for the means to control and influence. ${ }^{128}$ Cohen, however, reminds us that even market systems that are extensive, layered and apparently unregulated are still

\footnotetext{
121 Davilla (n 106) 375; Ezrachi and Robertson (n 105).

122 Chirita (n 116) 165.

123 Chirita (n 116) 152-3.

${ }^{124}$ Bundeskartellamt, 'Bundeskartellamt Prohibits Facebook from Combining User Data from Different Sources' (2019)

<https://www.bundeskartellamt.de/SharedDocs/Meldung/EN/Pressemitteilungen/2019/07_02_2019_F acebook.html> accessed 9 June 2021; Robertson (n 104) 16.

${ }^{125}$ Matthias Inverardi, 'German Court Turns to Top European Judges for Help on Facebook Data

Case' Reuters (24 March 2021) <https://www.reuters.com/article/us-facebook-germany-

idUSKBN2BG1PF> accessed 9 June 2021.

126 'Big Data: Bringing Competition Policy to the Digital Era - OECD' (n 111) 16; Marc Bourreau,

Alexandre De Streel and Inge Graef, 'Big Data and Competition Policy: Market Power, Personalised

Pricing and Advertising' [2017] Personalised Pricing and Advertising (February 16, 2017).

127 GSMA (n 54).

128 Inverardi (n 125).
} 
based on legal and regulatory constructs, ${ }^{129}$ and that mapping these constructs is an important task for research. If we wish to understand what kind of target for regulation the market presents, we should begin by understanding the legal constructs on which it is being built. Given that risk 'provides the basis for regulatory legitimacy', ${ }^{130}$ we use a comparison with other, non-financial, sectors - specifically food and medicine - to present an argument for how we should conceptualise the risk inherent in trading data as a commodity, in line with Aaronson's assertion that 'data is different' because trading and reusing it has implications for the people it reflects. ${ }^{131}$

We proceed in this section to compare the different layers and approaches present in sectoral regulation. We have demonstrated that although for the aim of formulating a normative approach to governing data at all, it is necessary to refer to something called 'the data market', once we go beyond the surface there are normative repercussions to an approach that aims to unify all the problems and promise of data under a single regulatory rubric. Given the multiplicity of different types of data source as discussed in section 3.1, we next consider whether the aim of regulation should be to govern the data market with the assumption of layering and decentralisation, as in the examples of food and medicine we analyse below, and thus potentially with the view of different data-generating communities' rights and entitlements in mind - or whether a unified approach such as the EU's proposed data governance act ${ }^{132}$ can adequately take into account the implications of this diversity.

With the comparisons that follow, we aim to demonstrate that for regulation to promote human needs and wellbeing in relation to the production, trading and use of a particular good, the different layers do not need to be procedurally harmonised. Instead, a shared core concept of 'safety', based on past experiences of harm, serves to establish the parameters and targets for these regulatory ecosystems. We choose to compare markets for risky and tangible goods (food and medicine) rather than risky and intangible ones (financial markets, for example). This is a normative choice: we posit that one central aim of regulating the data market should be to prevent immediate harm (as is the aim of food and medicine regulation) rather than to ensure the smooth functioning of the market and maximisation of the possibility for profit, as for example we do with financial markets.

Legislative points of reference include the passing of laws which explicitly create markets for data, one example being the overturning in 2017 of the US communication regulator's broadband privacy rules, so that internet providers were once again permitted to sell users' browsing histories without their knowledge. ${ }^{133}$ In the EU, the Regulation on the free flow of non-personal data of May 2019 formally established the freedom for EU countries to trade internationally in non-personal data. Moreover, 28 digital single market legislative proposals designed to create a digital single market

129 Julie E Cohen, 'Review of Zuboff's The Age of Surveillance Capitalism' (2019) 17 Surveillance \& Society 240.

130 O Bennett, 'From Safe Harbour to Sectoral Regulation: Deploying Financial Services Regulatory Theory to Address Disinformation in Content Recommender Systems. LL.M Dissertation, Submitted to the University of Edinburgh in September 2020.' 11.

${ }_{131}$ Aaronson (n 25).

${ }^{132}$ European Commission, 'Proposal for a Regulation of the European Parliament and of the Council on European Data Governance (Data Governance Act) COM(2020) 767 Final' (n 96).

133 Isha Srivastava, 'Uncertainty Surrounding the Repeal of the Internet Privacy Rules' (2018) 23 Intell. Prop. \& Tech. LJ 99. 
have been approved by the EU since 2014, ${ }^{134}$ all of which shape the way data can be shared and traded. Although they are often described as data privacy provisions, in fact data protection laws also create markets for data by providing legal certainty about what may and may not be traded, and by establishing rules around the portability of data which have the potential to create new intermediaries and business models. Data protection laws also have the effect of potentially certifying countries as having adequate data protection provisions, making it possible for them to trade data with other countries which have passed data protection rules (e.g. through 'adequacy' decisions). By 2021 there were 145 GDPR-based data protection laws in existence globally, with many more under discussion. ${ }^{135}$

Together this patchwork of laws, regulations, contracts and commons has the effect of building a framework - national and international - on which various practices of trading and extracting value from data can be based. We can see a recognition of this ad hoc data governance landscape, for example, in the G20's statement on financial inclusion, ${ }^{136}$ which advocates for the development and application of new payment infrastructures, identification technology and 'alternative data for credit reporting', all of which will create new worldwide markets for data and, correspondingly, new intermediaries to build, maintain and further develop those markets.

\subsection{Comparisons for regulation}

Given the complexity and multiplicity of the market, how might we think about regulating its functions and effects? Does the data market require a 'law of the horse ${ }^{137}$ - a dedicated framework drawn around its particular characteristics, or can it be governed using existing regulatory strategies? One way to test this is through a comparative lens, using examples from other systems. We provide a brief comparative analysis of two domains which each have something in common with the data market: food and medicine. These are very different commodities, which are subject to different regulatory regimes, but each to some extent can be seen as moving within a market which has more and less commercial elements; each poses potential risks to human needs and wellbeing in the case of market dysfunction, just as data does, and each requires some structure in which commodities can move internationally. The main difference between them, if we seek a just regulatory framework, is that data is only rhetorically a necessity. Although arguments are made that being able to trade and share data is of fundamental importance to human societies, these arguments are tied to economic logic, not to the fundamental rights that govern food and medicine.

\subsubsection{Food market regulation}

At the international, regional and national levels, food regulation is generally aimed at the protection of consumers and promotion of trade. In recent years, the European Union has made

\footnotetext{
${ }^{134}$ European Commission, 'The Digital Markets Act' (n 101).

135 Graham Greenleaf, 'Global Data Privacy Laws 2021: Despite COVID Delays, 145 Laws Show GDPR Dominance' (Social Science Research Network 2021) SSRN Scholarly Paper ID 3836348 <https://papers.ssrn.com/abstract=3836348> accessed 9 June 2021.

$136 \mathrm{GPFI}$ ' '2018 GPFI Progress Report to the G20 Leaders | GPFI' (2018)

$<$ https://www.gpfi.org/publications/2018-gpfi-progress-report-g20-leaders> accessed 9 June 2021.

${ }^{137}$ Frank H Easterbrook, 'Cyberspace and the Law of the Horse' [1996] U. Chi. Legal F. 207.
} 
attempts to modernise existing food legislation through the development of the European Commission Regulation No 178/2002, the General Food Law Regulation, so that food safety regulation is organised in a coordinated and integrated way. The development of food regulations has followed a series of food safety issues ranging from concerns about the use of hormonal growth promoters such as diethylstilbestrol, a synthetic estrogen, or compounds of diethylstilbestrol in veal calf production in Italy in the late 1970s to accelerate weight gain in farm animals, to reports from the late 1990s to the early 2000s of the presence of residues of Nicarbazin, a feed additive used for the treatment of coccidiosis in chicken. ${ }^{138}$ The use of Nicarbazin led to reports that coccidiostat residues were "increasingly reported in meat and eggs as a result of contamination of animal feedingstuffs". 139

At the international level, the Food and Agricultural Organisation (FAO) and the World Health Organisation (WHO) focus on safety. They advocate for the strengthening of countries' food control systems, ${ }^{140}$ so that national authorities can, when it comes to food, "protect public health, prevent fraud and deception, avoid food adulteration and facilitate trade", with legislation, infrastructure and enforcement mechanisms based on specific country requirements. McEvoy ${ }^{141}$ adds to this the importance of scientific principles and guidelines. The Codex Alimentarius Commission (CAC) is the intergovernmental body responsible for coordinating food standards and the harmonisation of food quality and safety. CAC's main objectives are the protection of the health of consumers and ensuring fair food trade practices. ${ }^{142} \mathrm{It}$ formulates standards for a wide range of food products and specific requirements covering pesticide residues, food additives, veterinary drug residues, hygiene, food contaminants, labelling, etc., which are then used (voluntarily) by governments.

A second layer of international regulation exists in the Agreement on the Application of Sanitary and Phytosanitary Measures (SPS) and the Agreement on Technical Barriers to Trade (TBT) under the World Trade Organisation (WTO). The SPS empowers WTO member countries to impose regulation and restrictions 'directly related to food safety', while encouraging them to apply only those measures necessary to protect consumers without restricting international trade. ${ }^{143}$ The TBT agreement, on the other hand, requires that technical regulations imposed by countries are not more restrictive on imported products than domestic ones.

The aims at the regional and national levels are similar to those at the global level. The European Commission advances principles and requirements for all sectors of the food chain, aimed at an integrated approach that defines the roles of different stakeholders, makes animal feed and food traceable, remains dynamic in terms of policy, and facilitates risk analysis and scientific advice. All

138 John DG McEvoy, 'Emerging Food Safety Issues: An EU Perspective' (2016) 8 Drug testing and analysis 511, 511; GM Fara and others, 'Epidemic of Breast Enlargement in an Italian School' (1979) 314 The Lancet 295; Food Standards Agency, 'Reducing the Incidence and Levels of Nicarbazin Residues in British Chicken. at DuckDuckGo' (2012) 6 <https://webarchive.nationalarchives.gov.uk/201204031http://www.food.gov.uk/multimedia/pdfs/nicarb azin.pdf> accessed 9 June 2021.

139 McEvoy (n 138) 513.

${ }^{140}$ FAO, 'Assuring Food Safety and Quality: Guidelines for Strengthening National Food Control

Systems' (FAO 2003) FAO FOOD AND NUTRITION PAPER 761

<http://www.fao.org/3/Y8705E/Y8705E00.htm> accessed 9 June 2021.

141 McEvoy (n 138) 511.

$142 \mathrm{FAO}$ (n 140) 4.

${ }^{143}$ FAO (n 140) 3-4. 
this is based on a combination of risk analysis with the precautionary principle, the latter coming into play where there is either proven or unknown risk. ${ }^{144}$ Other regional bodies such as the Caribbean Community (CARICOM) and the African Union through the African Organisation for Standardisation (ARSO) have introduced labelling and certification systems with the aim of increasing access to international markets. At the national level, legislation in the UK and the US, for example, establishes supervisory agencies and sets standards for safety, quality and labelling that extend throughout the food chain, from the production of food to its sale or supply to the final consumer.

There have been instances where despite food safety regulations, it has been difficult to prepare for or predict unexpected food safety challenges, or to address such challenges before consumers or trade are negatively affected. For example, during the Chinese milk crisis in 2007 and 2008 (FAO, 2008), Melamine, a chemical used to manufacture fertilisers, concrete and plastics, was added to raw milk and animal feed, ${ }^{145}$ leading to the death of six babies and making 300,000 people sick in China. ${ }^{146}$ Although imports of milk and milk products, including milk powder, originating in China are not allowed into the EU, there was concern that composite products 'might have reached the European Union's markets without undergoing systematic border checks' ${ }^{147}$ In response the European Commission imposed special conditions including the requirement that all Member States prohibit importation of milk products, carry out random checks and systematically test milk-related products from China. In the US, pet food contaminated with melamine had to be recalled after complaints of dogs and cats dying or becoming very ill after eating contaminated feed. ${ }^{148}$

\subsubsection{Regulating medicine}

The regulation of medicinal products for human use could be another useful point of reference for regulating data markets as it serves the combined objectives of ensuring the protection of health and the quality, safety and efficacy of medicines on one hand and ensuring the functioning of the market and stimulating innovation on the other.

No medicine is completely safe; unlike with ordinary consumer products on the market, patients are normally not equipped to make decisions about which medicines to use and how, and require professional advice. In some cases, healthcare professionals themselves often lack sufficient knowledge to make an informed choice on the quality, safety and efficacy of medicines. Ineffective or poor quality medicines can result in harm to individuals and distrust in the healthcare system at large; national governments are hence tasked with ensuring the protection and promotion of public health through establishing national authorities for regulating medicine. The regulation of medicine is both scientific and administrative in nature and covers a wide range of functions, including

\footnotetext{
${ }^{144}$ European Commission, 'General Food Law' <https://ec.europa.eu/food/horizontal-topics/generalfood-law_en> accessed 9 June 2021.

145 McEvoy (n 138) 514.

${ }^{146}$ BBC, 'China Dairy Products Found Tainted with Melamine' BBC News (9 July 2010) $<$ https://www.bbc.com/news/10565838> accessed 9 June 2021.

147 European Commission, 'COMMISSION DECISION of 14 October 2008 Imposing Special Conditions Governing the Import of Products Containing Milk or Milk Products Originating in or Consigned from China, and Repealing Commission Decision 2008/757/EC' <https://eurlex.europa.eu/LexUriServ/LexUriServ.do?uri=OJ:L:2008:273:0018:0020:EN:PDF>. 148 Department of Health \& Human Services, 'Review of the Food and Drug Administration's Monitoring of Pet Food Recalls (A-01-07-01503)' 1.
} 
licensing of manufacture, import/export, distribution, promotion and advertising of medicines; assessing medicines' quality, safety and efficacy, and issuing marketing authorisations; inspecting and surveilling the manufacturers, importers, wholesalers and dispensers of medicines; controlling and monitoring the quality and safety of medicines on the market; controlling the promotion and advertising of medicines; and informing professionals and the public. ${ }^{149}$

The modern regulation of medicines started to emerge after the progress in life sciences in the 19th century, which established "a solid foundation for modern drug research and development" ${ }^{150}$ Regulation was, however, mainly shaped by catastrophes rather than research: in 1938, the death of over 100 people in the US due to diethylene glycol poisoning resulted in the requirement for premarket notification for new drugs, and the 1950s brought the thalidomide disaster, where a medicine marketed as a cure for morning sickness caused an estimated 10,000 babies to be born with phocomelia, a condition involving shortened, absent, or flipper-like limbs. The drug was banned in most of the countries where it had been placed on the market by $1962 .{ }^{151}$

Thalidomide in particular led to more stringent medicine regulations being passed in the US, UK and $\mathrm{EU}$ in the 1960s, and the medicine regulatory system was reshaped to focus on the safety of medicines and adverse drug reaction reporting. In the mid-1970s, the EU further harmonised the standards as regards the testing of proprietary medicinal products and the legal, regulatory or administrative provisions relating to proprietary medicinal products. This started the process of harmonisation with an ultimate aim to create a common EU market for medicines. By the late 1980s, the need for wider harmonisation on a more global level had also been acknowledged, and in 1990 the International Conference on Harmonisation of Technical Requirements for the Registration of Pharmaceuticals for Human Use was established. ${ }^{152}$

Before being placed on the market, medicinal products need to be authorised, which is in the EU done either on the Member State or the European level via centralised, decentralised or mutual recognition procedure. The criteria underpinning this aim to establish suitable quality and a positive benefit-risk balance. ${ }^{153}$ The evidence on safety and efficacy of medicine ensues from clinical trials; once medicine is placed on the market, however, the monitoring of its safety and efficacy is subject to post-marketing surveillance, known as pharmacovigilance. ${ }^{154} \mathrm{EU}$ law does not (directly) regulate how medicines are used in practice.

\footnotetext{
${ }^{149}$ Lembit Rägo and Budiono Santoso, 'Drug Regulation: History, Present and Future', Drug benefits and risks: International textbook of clinical pharmacology (IOS Press 2008) 66-68.

150 Rägo and Santoso (n 149) 65.

151 Ibid, Barbara Fintel, Athena Samaras and Edson Carias, 'The Thalidomide Tragedy: Lessons for Drug Safety and Regulation | Helix Magazine' <https://helix.northwestern.edu/article/thalidomidetragedy-lessons-drug-safety-and-regulation> accessed 9 June 2021.

$152 \mathrm{ICH}$, 'ICH Guidelines. The International Council for Harmonisation of Technical Requirements for Pharmaceuticals for Human Use.' (Pharmaceutical Guidelines, 2019) $<$ https://www.pharmaguideline.net/ich/> accessed 9 June 2021; Rägo and Santoso (n 149) 66.

${ }^{153}$ Raphael European Commission, 'Legal Framework Governing Medicinal Products for Human Use in the EU' (Public Health - European Commission, 20 February 2017) <https://ec.europa.eu/health/human-use/legal-framework_en> accessed 9 June 2021. 154 European Commission, 'Competition: Report on Enforcement in Pharmacetical Sector' (European Commission - European Commission) $<$ https://ec.europa.eu/commission/presscorner/detail/en/IP_19_741> accessed 9 June 2021; European Commission, 'Legal Framework Governing Medicinal Products for Human Use in the EU' (n
} 
As mentioned, apart from protecting public health, the EU regulatory framework for medicinal products for human use also aims to ensure the free movement of medicines within the EU, thus creating a common market and promoting innovation. In this regard, the market framework for pharmaceuticals in the EU comprises both national and EU-level rules, namely rules on patents and pricing, the already mentioned marketing authorisation rules, as well as horizontal EU rules on the internal market freedoms and interventions aimed at improving the regulation carried out by the market itself. ${ }^{155}$ In this regard, antitrust rules have been quite extensively applied in the pharmaceutical sector, for example in cases of abuse of authorisation procedures, unfair and excessive pricing, agreements that block the entry of generic competition on the market, acts of blocking parallel pharmaceutical imports, etc. ${ }^{156}$

To conclude, the two distinct objectives of health protection and market regulation often intertwine and act in a mutually reinforcing way, which is reflected in regulation. In the EU, access to quality healthcare (products) can be seen as both an aspect of fundamental rights and social values, as well as a reflection of functioning pharmaceutical markets, which deliver "affordable medicines and more choice to patients and healthcare systems" ${ }^{157}$

\subsection{What can this comparison tell us?}

Food regulation at the global, regional and national levels puts into perspective the complexity of regulating chains of production, processing, storage and sale and can help us understand regulation of data market value chains. The Chinese melamine crisis highlights the challenges of controlling activities within a value chain: even when some actors within the chain take adequate safeguards for the protection of consumers, this may not guarantee consumer safety. The data market in most cases has a very integrated value chain, opaque to outsiders, so that attempts to control or adequately regulate data value chains may be elusive. As a result, just like a food value chain, it may be difficult to predict what future safety challenges may emerge and to guard against them. ${ }^{158}$ Responses to the unpredictable are therefore likely to be reactive rather than defensive. There may therefore be a need to consider whether, in addition to use of laws to govern the behaviour of actors within a chain, alternative modes of accountability can be included, such as an incentive system that increases actors' motivation to report problems.

Food regulation can also help consider the importance of holistic regulation of the data market, as a 'farm-to-table approach' as opposed to 'silo-based regulation' solely focused on protections available through data protection, privacy, cyber security or competition laws. Adoption of a holistic approach to the regulation of the data market may need to include, at international, regional and

153); European Medicines Agency, 'Authorisation of Medicines' (European Medicines Agency, 17 September 2018) <https://www.ema.europa.eu/en/about-us/what-we-do/authorisation-medicines> accessed 9 June 2021.

155 Leigh Hancher and Wolf Sauter, 'A Dose of Competition: EU Antitrust Law in the Pharmaceuticals Sector' (2016) 4 Journal of Antitrust Enforcement 381, 3-5.

156 Mary Guy and Wolf Sauter, 'The History and Scope of EU Health Law and Policy', Research Handbook on EU Health Law and Policy (Edward Elgar Publishing 2017) 22-23.

${ }^{157}$ European Commission, 'Competition: Commission Report Finds Active Competition Enforcement Contributes to Affordable and Innovative Medicines.'

$<$ https://ec.europa.eu/commission/presscorner/detail/en/IP_19_741>.

158 McEvoy (n 138) 515. 
national levels, the harmonisation of existing regulations that currently govern the data market (privacy and data protection laws, cybercrime laws, intellectual property laws, and trade laws including competition laws, consumer protection laws and private and public international law), to identify gaps that need to be filled, taking into account factors such as the evolving data market and the constant development of new technologies. Such harmonisation may help to create an adequate and comprehensive framework that will facilitate effective data control systems and the enforcement of risk-based data control strategies and laws to ensure 'data safety' for consumers, while promoting the effective functioning of data markets.

Useful parallels between medicine regulation and the data markets stem from the nature of medicinal products as potentially dangerous: data can be used directly to target an individual for negative treatment, or can have more indirect harmful results when used to manipulate or influence others. While the regulation of medicines is focused on quality, safety and efficacy of the marketed products, through which the protection and promotion of public (and individuals') health is achieved, as well as creating a common market for medicinal products, at least in the EU, it appears that the current regulatory framework for data (markets) is more concerned with directly protecting the individual themselves and their rights in the context of stimulating the movement of data (in the EU) across borders and infrastructures (i.e. data protection rules).

These two domains of regulation demonstrate that we may not need to have a granular vision of the entire market in order to regulate it, but that instead it is of central importance to know what values and risks we are regulating for. If we can come close enough to an international consensus on values and constraints, then an interlocking system of international, regional and national controls can enact those on different elements and activities within the broader whole. These two regulatory systems demonstrate dynamic capacity, learning and changing over time as different challenges arise. They are driven both by developments in science and by the emergence of new risks, and are built in ways which empower regional and national actors to take immediate action if harm is occurring. They both demonstrate that only a holistic model can govern a diverse set of activities spread across countries and conducted in both commercial and non-profit space, with both taking a supply chain approach that allows for regulation of production as well as distribution and use. Neither chooses a particular point in the supply chain as the regulatory target: instead each defines a commodity according to its end use (nourishment; treating disease) rather than its starting point as seeds or chemicals. Finally, unlike the regulation of data, each of these models is based on the assumption that the risk of harm to consumers is impermissible, rather that something to be weighed and assessed by commercial actors in relation to business interests.

The gaps both these systems point out are also relevant for regulating data, however. The catastrophes that have driven both models to evolve serve to highlight the difficulty of creating the right incentives to make incipient harm visible and preventable. This responsibility falls mainly on sub-national systems such as inspections and reporting, which are often under-resourced and may be considered the weakest links in the system. Strong international rules and reporting infrastructures are easily undermined by corruption amongst local inspectors. They also demonstrate that predicted risk cannot be the sole criterion for deciding how to regulate, and who should be accountable. Instead they reveal a tension between the notion that the commodities they seek to govern are inherently risky; that they are essential for fulfilling people's rights, and that they 
are an economic commodity whose production and trade create broader benefits. These tensions are balanced using a precautionary principle, but this nevertheless leaves space for error and disaster.

The possibility of adopting a view of data regulation as aiming primarily for harm prevention, rather than market expansion, has immediate relevance for current debates on data governance around the world. The new Data Governance Act under discussion in the EU, like the proposed Indian NonPersonal Data Governance Framework, ${ }^{159}$ makes the case for an economic value approach to data regulation overall, into which data protection fits as a safeguard against the potential for harm inherent in that overall approach.

\section{Conclusion}

We have explored the state of research on the nature of the data market, its relationship to other types of market, and the implications of these for thinking about regulation. The value chain perspective is one useful way to begin to understand the landscape of the data market, as it leaves space both for the different market activities and actors, and for the different types of data commodities that may be traded and shared, ranging from bits and bytes to models and inferences. Our perspective has remained purposely broad, and has therefore diverged from much of the literature on the data market which focuses on what is most visible: personal data, and the highprofile markets relating to digital advertising exchanges and practices such as credit scoring.

It is important to acknowledge that developing clarity on values and risks is not enough for effective regulation, particularly given the demonstrable geopolitical and economic power of technology multinationals and their history of claiming exceptionality when it comes to their own interests. We have, however, argued here that it is not possible to formulate an idea of what effective regulation would be when we cannot clearly define the target of that regulation - and that understanding the particular risks and values involved in trading data is essential to doing so.

Instead, we ask what might be the starting points for a holistic regulatory view of the ways in which data is created, traded, shared, distributed and used which can take into account the human value that is inseparable from digital data. The examples of food and medicine regulation suggest there is something to gain from an approach that addresses a commodity from the perspective of its effects on society, and that derives the need to regulate from those effects, whether risky or beneficial. All digital data derive from society and culture - including when machines speak data to machines - and all digital data, similarly, have social effects, whether those effects are linked to economic value or other types of value such as the scientific, the medical, or the creative. If we step back from a purely economic focus and try to address this whole assemblage as deriving from us, and ultimately affecting us at the end of its value chain, we acquire both a different perspective on what might constitute 'the data market' and why (and how) we might want to regulate it.

159 Government of India, 'Expert Committee Report on Non-Personal Data Governance Framework' (Ministry of electronics and information technology, India 2020) 111972/2020/CL \& ES $<$ https://prsindia.org/policy/report-summaries/non-personal-data-governance-framework> accessed 6 September 2021. 
This more holistic vision takes us beyond the tension between surveillance and economic value creation to the structural level, where sites of data exchange can help us understand both economic and political power, and can reveal how different markets are shaping our societies. Power accrues to those who can aggregate data, but this is not merely economic power that can be controlled with antitrust provisions and trade dialogues. It is power over human development: over agriculture and learning, innovation and creativity, and if we look only at the economic effects of that power to aggregate data, we miss many of the central reasons we may want to regulate the market.

The fields of medicine and food offer different visions of harm and response: a risk-based vision where industry is responsible for identifying possible harm; a harm-based one where regulation is only activated if harm is identified, and a precautionary one where any activity must be demonstrated to be safe before it can be permitted. None of these on its own provides the kind of approach we might wish for digital data: on the one hand its free creation and movement can underlie important freedoms such as speech, identity-building and association, but on the other its capture by purely market forces can result in the exacerbation of inequality and the creation of new vulnerabilities amongst almost all in society.

What kind of regulatory approach might help us balance these considerations? The first lesson from other fields is that it should be multi-level - global as much as local - to avoid building in a bias toward either facilitating or capturing trade, given the different motivations at higher and lower levels. Second, lessons from other domains of regulation suggest that it should be rooted in common values on the global level, as this appears to be key in motivating powerful actors to seek out and remedy problems: effective harm prevention is not possible where trade and value extraction outweigh other priorities. Establishing fora for dialogue between the national and international levels also appears important if we wish to regulate for a balance between harm prevention and value creation. Public values in relation to the data economy do not spring fully-formed from fundamental rights in the same way they seem to around medicine and food (although these processes of establishing common values have also been nuanced and complex). Instead they must be surfaced, debated and shaped to inform regulation. Lastly, the overall conclusion from our analysis is that a normative approach based on the idea that the direction of data's lifecycle is always outward from the groups originally represented, and toward a more general societal and economic value, may be misguided. Instead, a regulatory approach that explicitly aims to balance the representation of those who are reflected in the data, with the needs of society more broadly, would be infinitely more complex and troublesome yet ultimately more normatively justifiable. Placing concerns of the equitable distribution of data's benefits, and equitable protection from negative impacts, at the centre of the regulatory process would be disruptive yet democratic, and would have cascading effects on business, research and government which would ultimately make data not a commodity but a democratic good.

This suggests a regulatory vision that addresses data as a factor in human development which interacts with that human development differently according to geography and politics, rather than a stable commodity such as medicine which can be addressed as a necessity in much the same way around the world. With data it is less about distributional equity and safety than its ability to interact positively, rather than negatively, with existing conditions of society and economy. The challenge for regulation, then, is to hold the local and specific in balance with the international and complex: to 
Forthcoming (2022) in Law, Innovation and Technology

find a global approach with which to address the entire assemblage as more than the sum of its parts, but also to gain traction on the data economy on the local level. Doing so is the challenge of the next decades, and just as with other global commodities linked to rights and development, there are no shortcuts. 